\title{
ALGUNAS CONSECUENCIAS DE DOS PRINCIPIOS PEIRCEANOS
}

\author{
Wenceslao Castañares
}

(Universidad Complutense. Madrid)

En la época en que Peirce trataba de afirmar sus ideas sobre el pragmatismo publicó un artículo con el título de «Some Consecuences of Four Incapacities» 1 . Lo que entonces pretendía Peirce era negar cuatro principios básicos de la filosofía de Descartes y extraer de esta negación algunas consecuencias importantes para la filosofía pragmatista. De la importancia de este artículo para conocer las ideas fundamentales de esta primera época del pensamiento de su autor es muestra la reiteración con que han sido citados algunos de sus párrafos. Sin embargo de lo que ahora se trata no es tanto recordar o comentar las ideas que allí expone Peirce, sino recoger su espíritu. Lo que aquí se persigue es afirmar dos principios básicos de la teoría semiótica de Peirce con la intención de sacar algunas consecuencias de carácter general que pueden afectar también a la teoría literaria. He de advertir, sin embargo, que se trata más de

1 Este artículo apareció en el Journal of Speculative Philosophy, 1968, 2. Posteriormente ha sido recogido en los Collected Papers, vol. 5, párr. 264-317. En castellano poseemos una versión en la antología publicada por J. Vericat (E. Crítica, 1988, pp. 82-122). 
un programa a desarrollar que de una propuesta que pueda ser considerada suficientemente articulada en todos sus detalles.

\section{PRIMER PRINCIPIO}

Cuando, hace ya algunos años, la crítica postestructuralista llegó al convencimiento de que el signo (su noción de signo, habría que precisar) debía ser sustituido por el texto, se acuñó una especie de consigna que proclamaba con cierto aire provocativo que la semiótica ya no era «la ciencia de signos». Tal consigna, más allá de la provocación, alude a algo bastante obvio desde mi punto de vista: la semiótica no puede ser meramente la ciencia de los signos si éstos son entendidos de la forma en que se hace generalmente si se siguen los principios estructuralistas.

Una lectura superficial — quizá por demasiado literal — de la obra de Peirce podía llegar a concluir que su semiótica sí es una ciencia de los signos. Sin embargo eso no es más que una forma de hablar que, si bien en cierto modo es también la del mismo Peirce - hay que reconocerlo-, encubre una verdad no tan profunda: su semiótica es la ciencia de la semiosis. Cualquier definición de signo (o representamen, según los casos) no puede sustraerlo a su condición de relato de una relación irreductiblemente triádica en la que intervienen, además del signo, el objeto y el interpretante. Fuera de ella el signo es absolutamente inconcebible. Esa relación triádica es, simplificando, la semiosis.

El desconocimiento de este hecho (que es una obviedad para cualquier mediano conocedor de Peirce), ha sustentado no pocas críticas que erraban el blanco porque no apuntaban más que a fantasmas. Tales críticas no merecen, pues, más que la indiferencia.

Ahora bien, si va reconociéndose a la semiótica como ciencia de la «naturaleza esencial y variedades fundamentales de la semiosis posible» (5.488) ${ }^{2}$, no se han sacado —o todavía no se han desarrollado lo suficiente-algunas consecuencias que de este principio se derivan.

1.1. Una de ellas puede ser la superación de dos concepciones de la semiótica no muy alejadas entre sí, a pesar de las apariencias. La primera considera que no es posible una teoría general y única que sea capaz de

2 En adelante, siempre que aludamos a textos de Peirce recogidos en los Collected Papers, citaremos sus párrafos como suele hacerse habitualmente: la primera cifra se refiere al volumen y las que la siguen, separadas por un punto, al párrafo correspondiente. 
dar cuenta de cualquier clase de semiosis (y por tanto de cualquier tipo concebible de signo). La segunda mantiene que el auténtico objeto de la semiótica es el texto linguíístico y, consecuentemente, que la teoría lingüística elaborada desde este supuesto - y los análisis que inspirados en ella pudieran realizarse-, resulta sin más aplicable a cualquier otro fenómeno significativo.

Ambas sufren de lo que podríamos llamar «prejuicio lingüístico». La primera considera que las lenguas naturales constituyen un medio comunicativo tan específico y diferenciado que los signos «no lingüísticos» apenas tienen algo que ver con él: se trata de fenómenos tan dispares que resulta muy difícil - si no imposible - elaborar una teoría que abarque a todos ellos. Consecuentemente, resultaría más efectivo separarlos conceptualmente y distinguirlos terminológicamente.

La segunda no sólo mantiene que el lenguaje constituye el medio de comunicación más elaborado y complejo que el hombre posee, sino que no hay sistema de comunicación o significación que no sea traducible o reducible a las lenguas naturales. Cualquier otra manifestación sígnica, carece de interés por sí misma, ya que el estudio del lenguaje satisface todo tipo de necesidades. Como decía $\mathrm{R}$. Barthes, desde este punto de vista la semiótica no puede ser más que una «translingüística».

Otra manifestación de este mismo prejuicio -desde luego más ingenua que las anteriores, aunque a veces va unida a ellas- es la identificación que con frecuencia se hace de palabra con signo. Se trata de algo que puede parecer excesivamente grosero desde el punto de vista intelectual como para aparecer, tal cual, en una teoría semiótica mínimamente seria. Sin embargo no resulta tan difícil encontrar en algunos autores una inclinación - puede ser que un tanto inconsciente - a realizar esta identificación. Al fin y al cabo, los ejemplos que se suelen poner cuando se habla de la cuestión resultan ser nombres, pocas veces una oración y, desde luego, difícilmente un texto. Se trata, por lo demás, de una práctica que tiene una larga tradición histórica.

La superación que la semiótica de Peirce lleva a cabo de este «prejuicio lingüístico» no supone la negación de lo que constituye un acuerdo bastante general: el lenguaje es el medio privilegiado por el que el hombre no sólo se comunica con otros hombres, sino por el que se constituye a sí mismo y al mundo que lo rodea. Pero ello no puede hacernos olvidar que, si bien el hombre no puede pensar sino por medio de signos, éstos no son únicamente lingüísticos. Consecuentemente, una teoría semiótica debe dar cuenta de cualquier tipo concebible de signo, incluidos aquellos que no son específicamente humanos.

Por lo que se refiere al signo lingüístico no puede caber duda alguna: signo puede ser tanto una palabra o una frase como un texto o una obra completa. La complejidad sintáctica es, a estos efectos, irrelevante. 
Por lo demás, la eliminación de este prejuicio quizá pudiera conseguir algunos efectos semejantes a los que Kant esperaba con su «giro copernicano»: planteémonos a título de hipótesis si no explicaremos mejor ciertos fenómenos lingüísticos desde una teoría que considere como objeto inmediato cualquier tipo de signo $-\mathrm{o}$ texto-. Tampoco debería olvidarse la advertencia que Peirce hacía a una famosa amiga al final de una carta fechada el 14 de marzo de 1909: «Pienso, querida Lady Welby, que tal vez esté usted en peligro de caer en algún error como consecuencia de limitar tanto sus estudios a los lenguajes y entre éstos a algunos tan peculiares como lo son todos los arios y, en ese marco, dedicarse tanto a las palabras».

1.2. Otra consecuencia sería la revisión - si no el rechazo en algunas de sus formulaciones- del principio de inmanencia del texto lingüístico. Transportado a la semiótica desde la lingüística (una lingüística que nos remite a aquellos tiempos en que trata de constituirse como ciencia «estricta» y «autónoma»), podría ser considerado como un efecto más de lo que antes hemos llamado "prejuicio linguiístico». Históricamente considerado, puede concebirse como un mecanismo de defensa que se pone en marcha para evitar cualquier contagio «filosófico»: había que evitar entrar en discusiones de orden ontológico que podrían colarse por el portillo de las realidades objetuales que, según dice, son extralingüísticas.

Esta actitud defensiva es producto tanto de los excesos de filósofos que se ocupan de algunos problemas semióticos, como del temor de lingüistas y semiólogos demasiado aprensivos. La elección del término «objeto» para referirse a «lo significado por el signo» 0 «aquello a lo que el signo representa» ha facilitado, por el uso que de él se ha hecho muy frecuentemente en la tradición filosófica, su interpretación como algo «real» o «verdaderamente existente». Las extensas y, en ocasiones, complejas discusiones originadas por ello, son conocidas.

Pero desde la teoría de Peirce, el objeto es un relato necesario de toda semiosis y en cuanto tal no puede ser expulsado de la problemática semiótica. Dado que el «objeto de un signo» puede se real o ficticio, las discusiones ontológicas, gnoseológicas o espistemológicas pueden ser perfectamente obviadas por la semiótica. No era esto, sin embargo, algo que pudiera preocupar a Peirce, al que hay que considerar necesariamente filósofo. Para él, el objeto de la semiótica es el objeto inmediato que es también una representación (y desde ese punto de vista un signo). Pero hay otra consideración del objeto: el que llama objeto dinámico (que puede ser real) y que es, en sentido más amplio, lo que el signo representa $o$ aquello a lo que sustituye. El objeto dinámico queda fuera de un acto 
concreto de semiosis: se trata de una realidad que no sólo desborda sino que determina al signo.

Precisando un poco más, aunque con la brevedad que el caso exige: la constitución del objeto se realiza por dos caminos: desde la realidad misma, a la que accedemos por la percepción, y por medio de procesos semiósicos. Como queda perfectamente claro ya desde sus primeras obras ${ }^{3}$, Peirce mantiene que nuestras creencias verdaderas están determinadas por la existencia de un mundo real, y es esto lo que nos permite diferenciarlas de aquellas otras que son ficticias. Pero la realidad de los objetos es inconcebible al margen de sus representaciones y por tanto al margen de los procesos semiósicos.

Si esto es así, el análisis semiótico puede encontrarse con la necesidad no sólo de recurrir a otros textos sino incluso a los objetos, que aunque tengan ya el carácter de representados, tienen su origen en una experiencia que no es necesariamente concebible como lingüística. Quiérase o no, la semiótica da por supuestos principios que pueden considerarse filosóficos y por su parte, la epistemología - al memos la peirceana - no puede concebirse sin la semiótica.

1.3. La tercera consecuencia afecta al tipo de análisis que es posible hacer desde una teoría semiótica de inspiración peirceana. La tendencia a considerar la semiótica de Peirce como mera ciencia de los signos, puede conducirnos a la convicción de que lo que puede hacerse al aplicarla es simplemente una descripción del tipo de signos que un texto determinado pone en uso. Desde mi punto de vista, esta actitud concibe a Peirce de forma restrictiva, y encierra el peligro de que, a medio plazo, esta vía quede agotada.

Una de las partes de la semiótica de Peirce que ha sido considerada como más original y, desde el punto de vista práctico, la que ha reclamado mayor atención, ha sido la dedicada a la clasificación de los signos. Pero al margen de cualquier valoración, no es menos cierto que se presta a utilizaciones parciales. No debería olvidarse que, al ser una clasificación formal y, por tanto, a priori, no resulta nada fácil, como el mismo Peirce reconoce, asignar un contenido a cada una de las sesenta y seis clases válidas de signos. Tampoco debe perderse de vista que la clasificación se realiza tomando como criterio las relaciones que un signo mantiene dentro de la semiosis. Al ser tres estas relaciones, las clasificaciones han de contener, al menos, tres categorías definitorias. Decir de un signo, por ejemplo, que es un icono, es una descripción que se limita a

3 Puede verse especialmente uno de los artículos más conocidos de Peirce: «How to Make Our Ideas Clear». Publicado en 1878, ha sido recogido en los Collected Papers, 5.248-271. En castellano existen dos versiones publicadas por las editoriales Aguilar (1971) y Crítica (1988). (Véase bibliografía). 
ver un aspecto: sólo contempla el tipo de relación que mantiene con su objeto. Un análisis que contemple todas las relaciones posibles, ha de ser necesariamente prolijo y complejo.

Algunas de sus aplicaciones (las que se realizan a mensajes publicitarios pueden ser uno de esos casos), aunque todavía están en fase bastante embrionaria, apuntan hacia cuestiones interesantes. Pero no ocurre esto con la mayor parte de los análisis que he podido llegar a conocer. Por referirme a algunos de ellos: no acabo de estar convencido de que su aplicación a los textos literarios resulte lo suficientemente relevante.

Pero aparte de esto, ese tipo de análisis suelen caer en la tentación de considerar signos sólo a las palabras o como mucho a expresiones que ni siquiera llegan a la complejidad de una oración. Este reduccionismo es rechazable no porque traicione la teoría de Peirce (no hay por qué considerar negativamente la «traición» a una teoría si los resultados a los que conduce son fructíferos) sino porque pretende recorrer un camino ya rechazado por intransitable desde concepciones no peirceanas. Este hecho debería hacernos reflexionar.

Desde mi punto de vista, existen en la teoría de Peirce otras nociones que pueden resultar más esclarecedoras para el análisis semiótico que la comentada. Tales son la consideración de la semiosis como proceso limitado y el papel que en este proceso juega el interpretante. Esto es, precisamente, lo que me ha llevado a proponer un segundo principio como motivo de reflexión.

\section{SEGUNDO PRINCIPIO}

Son varios los aspectos del interpretante que podrían ser considerados relevantes, pero quizás ningún otro como el de «signo equivalente o tal vez más desarrollado» al que alude Peirce en una de las definiciones más conocidas (2.228). Podría añadirse «efecto creado o producido en la mente de una persona» si no fuera por lo poco satisfecho que le dejaba la expresión. Pero, por mucho que le pesara, no cabe duda de que ayuda bastante a entender su concepción de la semiosis como un proceso en que un signo produce un interpretante y éste, convertido ya en signo, otro interpretante, y así en una serie de duración indefinida.

Las consecuencias que pueden derivarse de este principio no se reducen a las que aquí aludiremos, pero al menos queremos destacar las tres siguientes: 
2.1. Durante mucho tiempo y desde posiciones de orígenes diferentes (estructuralismo, teorías de la información, teoría de los actos de habla...), a la hora de describir los procesos comunicativos, se ha coincidido en un esquema que, reducido, contemplaba tres elementos básicos: emisor, receptor y mensaje. Este esquema privilegiaba, además de una concepción del significado como algo dado, la producción (actividad) sobre la recepción (pasividad).

Frente a estas concepciones, la semiótica de Peirce permite contemplar los procesos de comunicación desde el punto de vista de la recepción sin que por ello haya que olvidarse del acto de creación. El interpretante de un signo se encuentra siempre en esa situación de intermediación que, hacia atrás, nos remite a un signo, pero hacia adelante, él mismo es un signo que produce un interpretante nuevo. El hecho de que desde la teoría pueda explicarse convincentemente que sin interpretante no hay signo, sin duda puede ir más allá que la repetida constatación de que no hay obra sin lectores. La importancia de este principio no sólo afecta a la pragmática. Unido a la explicación de los procesos semióticos como procesos inferenciales (y más concretamente a la teoría de la abducción) puede facilitarnos la comprensión y explicación tanto del acto de creación como del de recepción.

2.2. Las conclusiones a las que se ha llegado desde la teoría de la recepción han llevado a revisar la concepción de los sistemas comunicativos como códigos. Sus insuficiencias han sido reconocidas incluso por semiólogos (el caso de U. Eco resulta paradigmático) que en otros tiempos fueron sus defensores.

La concepción peirceana del interpretante como efecto producido por un signo y al mismo tiempo como regla de interpretación ${ }^{4}$, permite explicar cómo es posible conciliar lo general (regla) con lo particular (uso). Aplicada esta teoría a problemas como el del estilo, no nos sería necesario recurrir a nociones como la del «grado cero» a partir del cual el estilo literario es un «abuso», «desviación», «infracción», «subversión» o cualquier otra sugerencia que suponga normas de interpretación más o menos estrictamente codificadas.

2.3. Pero si la semiótica peirceana es un freno para teorías de la interpretación que adolecen de rigidez como la citada, puede serlo también para aquellas que se sitúan en el extremo opuesto, como es el caso de la

4 Habría que precisar que Peirce distingue tres tipos de interpretantes: inmediato, dinámico y final. Los tres son efectos producidos por un signo, pero sólo el final puede ser entendido propiamente como regla. Para mayores precisiones pueden verse: C.P. $4.536,4.572,5.475-476$ y la carta a Lady de Welby de 14 de marzo de 1909. 
deconstrucción derridiana. Un lector puede abusar del texto justamente porque las normas que lo rigen permiten (en unas ocasiones más que en otras, claro está) una aplicación flexible. El abuso del texto significa el rechazo del interpretante como regla que, como tal, está basada en lo que podríamos llamar «el acuerdo de una comunidad de lectores». Sin este principio social (que sustenta, como subraya Peirce, la lógica y la semiótica) la lectura se convierte en privada y, llevado hasta el último extremo, el texto puede, paradojicamente, convertirse en algo de lo que ya no se puede hablar porque él mismo ya no habla. Llegaríamos así a la interrupción del proceso de semiosis ilimitada o, si se prefiere, de la conversación entablada entre el autor y el intérprete que toda lectura supone. Entre el significado como algo dado de antemano y la deriva incontrola$\mathrm{da}$, existen muchas situaciones intermedias. El interpretante puede ser un signo equivalente o, en la mayor parte de las ocasiones, un signo más desarrollado, pero eso no justifica la interpretación arbitraria que elude la coerción que el carácter social de la norma impone.

\section{Referencias bibliográficas}

HaRdwick, CH. S. (ed.) (1977): Semiotics and Significs: The Correspondence between Charles S. Peirce and Victoria Lady Welby. Bloomington: Indiana University Press.

PeIrce, Ch. S. (1931-1958): Collected Papers, vols. 1-8, Ch. Hartshorne, P. Weiss and A. W. Burks, (eds.), Cambridge MA: Harvard University Press.

- (1970): Deducción, inducción e hipótesis, Juan Martín Ruiz-Werner (ed.). Buenos Aires: Aguilar.

- (1971): Mi alegato en favor del pragmatismo, Juan Martín Ruiz-Werner (ed.). Buenos Aires: Aguilar.

- (1978a): Lecciones sobre el pragmatismo, Dalmacio Negro Pavón (ed.). Buenos Aires: Aguilar.

- (1978b): La ciencia de la semiótica, Armando Sercovich y B. Bugni (eds.). Buenos Aires: Aguilar.

- (1982-1989): vols. 1-4, The Writing of Charles S. Peirce A Chronological Edition, M. H. Fisch, E. C. Moore and C. J. W. Kloesel (eds.). Bloomington: Indiana University Press.

- (1987): Obra lógico-semiótica, Armando Sercovich (ed.). Madrid: Taurus.

- (1988): Escritos lógicos, Pilar Castrillo (ed.). Madrid: Alianza.

- (1988): El hombre, un signo, José Vericat (ed.). Barcelona: Crítica. 